\title{
Kauko Tom and d'Amato Maurizio (Eds.): Mass Appraisal Methods. An international perspective for property valuers, 2008, Wiley-Blackwell, pp. 319, ISBN: 978-1-4051-8097-9
}

\section{Caroline Schaerer}

Received: 27 April 2009/Accepted: 28 July 2009/Published online: 4 September 2009

(C) Springer Science+Business Media B.V. 2009

The book Mass Appraisal Methods-An international perspective for property valuers presents and reviews the techniques of mass appraisal that are currently used in different countries. In addition to the rather traditional techniques, it also discusses innovative and emerging methods. Aside from reviewing their relative performances, the book reveals that the development and the choice of the optimal appraisal method for property valuations should be based on criteria reflecting the particular property market environment where the valuation takes place. Indeed, due to countries' specific institutional contexts and regulations, a mass appraisal methodology that is pertinent in a given property market situation may not be suitable for other property markets. Given that the different appraisal methods apply to different contexts, none of the proposed mass appraisal methods can be said to be more efficient than another.

The different methods of mass appraisal reviewed in the book are subdivided into two groups: the traditional property valuation methods, referred to as the orthodox methods; and the emerging methods, referred to as heretic techniques. The most popular and commonly used mass appraisal method belonging to the orthodox category is the hedonic approach. However, the book editors insist that the hedonic model may not capture all the information needed to determine property market value. It is correct that the hedonic model is based on the strong assumption that the housing market is in equilibrium. Obviously, the assumptions underlying the standard hedonic price models are not fulfilled on real markets, in which imperfections such as rent regulation, high heterogeneity of dwellings, barriers to housing supply, and high search and moving costs are well known. I should, however, emphasise that this caveat does not necessarily render the hedonic model worthless. On the contrary, being aware of the limitations of the model allows one to take them into account directly when modelling the hedonic equation. Some researchers have even used hedonic models to reveal and measure the consequences of market imperfections. For example, in

C. Schaerer $(\bowtie)$

Geneva School of Business Administration (HEG-Ge), Center for Applied Research in Management (CRAG), University of Applied Sciences of Western Switzerland (HES-SO), 7 route de Drize,

1227 Carouge, Geneva, Switzerland

e-mail: caroline.schaerer@hesge.ch 
order to correct for the asymmetry of information, a hedonic model can account for the fact that house prices are generally negotiated bilaterally rather than set by an auctioneer on a perfect market. The resulting bargaining effects on the housing market can be estimated using the hedonic model (see Knight 2008). In the same vein, Chap. 6 of Mass Appraisal Methods presents some extensions to the hedonic model that account for the spatial dependencies in the housing markets.

Nevertheless, as emphasised by Thompson in Chap. 2, it is obvious that the performance of appraisal methods depends above all on the availability of good and reliable data and on the sound stratification of the market. Indeed, the data requirements in the hedonic model are particularly high since this model is deterministic in the relationship between property prices and characteristics. In case good quality and reliable data are not available, the editors argue that the application of emerging methods can be helpful. These heretic techniques bring more flexibility into the property value calculations as they are not related to any theoretical assumption.

Considering the above, the book contains fourteen chapters divided into four main parts. The first part, from Chaps. 2-5, covers the current mass appraisal practices. In Chap. 2, Thompson presents a modelling process that combines the automated comparable sales technique and multiple regression analysis. In Chap. 3, Borst and McCluskey present a modified comparable sales method that is based on a measure of dissimilarity between the different properties. Op't Veld, Bijlsma and Van de Hoef explain, in Chap. 4, how the market value of any house in the Netherlands is assessed using a web application that allows for valuing any house given its characteristics based on a hedonic model. In light of the practices described in these chapters, we note that multiple regression analysis for mass appraisal is currently used in the US and Dutch property markets.

In Chap. 5, d'Amato and Siniak argue that when the market is non-competitive or when competition is only emerging, there should be no expectation of assessing the exact value of a property. They describe how fuzzy numbers can be used in such cases and then illustrate this mass appraisal technique by showing an application to the property market in Belarus.

The second part of the book (Chaps. 6-9) deals with current advanced methods. It concerns principally the spatial heterogeneity of property markets and the necessity of incorporating spatial characteristics in the property valuation process. More specifically, in Chap. 6, Des Rosiers and Thériault illustrate how urban externalities such as accessibility to urban services and proximity of high-voltage transmission lines can be accounted for in the hedonic model and how spatial heterogeneity can be modelled. In Chap. 7, Renigier shows that the spatial analysis of the residuals can be very informative for predicting property values with enhanced precision. In Chap. 8, Francke presents hierarchical trend modelling, a statistical model which accounts for time and spatial dependence.

The third part of the book describes the emerging heretic methods. In Chap. 9, Strumpf Gonzalez presents a flexible model for mass appraisal using fuzzy systems based on a neural network and genetic algorithm. In Chap. 10, Kauko presents two modelling techniques: the self-organizing map, which refers to data pattern recognition and clustering; and the analytic hierarchy process, which is about decision analysis and expecting judgements to uncover additional information from the data. Finally, in Chap. 11, d'Amato introduces the rough set theory valuation method that relies on internal knowledge provided by the data.

This volume makes an interesting contribution to the literature on mass appraisal techniques. It is well written and clearly structured. That said, the inclusion of Chap. 5 among the current methods (first part of the book) instead of the emerging methods (third 
part) is questionable, particularly because fuzzy numbers are apparently not used in current valuations of the Belarusian property market. The chapters are generally accessible, although the mathematical developments can be rough-going, especially in the chapters on emerging methods. Nonetheless, its major advantage is that it gives the state of the art of property valuation methods, including examples of current practices in the property markets. When referring to mass appraisal techniques, one usually thinks of hedonic and comparable sales methods. Hence, presenting and explaining the development and advances of heretic techniques in mass appraisal is very instructive. In addition to the property valuers, this book may therefore be of interest to the academic community as well.

\section{Reference}

Knight, J. R. (2008). Hedonic modeling of the home selling process. In A. Baranzini, J. Ramirez, C. Schaerer, \& P. Thalmann (Eds.), Hedonic methods in housing markets. Pricing environmental amenities and segregation. Springer: New York. 